Egyptian J. Anim. Prod. (1996) 33 (2): 153- 161

\title{
THE INFLUENCE OF EXTENDED POSTHATCH HOLDING TIME AND PARENT AGE ON PHYSIOLOGICAL AND IMMUNOLOGICAL PARAMETERS OF BROILER CHICKS
}

\author{
A.M. Atta, A.A. Atallah, S.M.T. El-Tantawy and F.R. Mohamed \\ Department of Animal Production, Faculty of Agriculture, University of Cairo, Giza, \\ Egypt
}

\section{SUMMARY}

The objectives of this study were to determine the effect of posthatch holding time in the incubator and age of parent on physiological and immunological parameters. Eggs from Arbor Acres breeders aging 37, 44 and 67 weeks were hatched. Half of the chicks from each parent age group were removed shortly after hatching, the other half was kept in the hatcher for an additional $30 \mathrm{~h}$ (held).

Held chicks had significantly lower residual yolk at the day of placement, relative bursa weight (RBW) (except those from youngest hens at 2, and 6 weeks of age) and relative spleen weight (RSW) at 2, 4, or 6 weeks of age for chicks from 37, 44 or 67 weeks-old-hens, respectively. On the other hand, these held chicks produced lower antibody titter (however not significant) against sheep red blood cells (SRBC), and significantly elevated maternal antibody titter against Newcastle disease (NDV). Also, held chicks from youngest hen had elevated PCV at the day of placement.

Relative residual yolk and antibody titter against SRBC were positively increased with the age of parent, whereas RBW of chicks from 44-week-old hens ranked first at 4 and 6 weeks of age. However there was no influence of parent age on PCV, RSW or antibody titter against NDV.

Keywords: Broiler, posthatch, holding, parent age, immune response

\section{INTRODUCTION}

The uttimute goal of commercial hatcheries is to produce good quality chicks, with the highest hatchibility as economically as possible. To ensure the highest hatchability, incubation schedules tend to be tailored to the latest hatching chicks (Hager and Bean, 1983). Therefore, some chicks may be held for extended times before the hatch is pulled. The extended holding in the hatcher is associated with deterimental effects on general health, thriftiness leading to mortality of newly hatched and growing chicks. The deterimental effect of long hatching holding times attributed to dehydration (Kingston, 1979; Moran and Reinhart, 1980; and Wyatt et al., 1985 and 1986), low immune responsiveness and grat susceptibility to infectious disease (Wyatt et al., 1986 and Casteel of al., 1994).

issued by The Egyptian Society of Animal Production 
Chicks quality is also affected by the age of parent stocks. The chicks from old hens exhibit lower mortality (Hays and Spear, 1952 and McNaugton et al., 1978), heavier and higher growth rate than the chicks from young hens (Sinclair et al., 1990).

The objectives of this study were to evaluate the influence of parent age and the time chicks were held posthatch in the hatcher, on physiological parameters associated with the immune response.

\section{MATERLALS AND METHODS}

\section{Prehatch and posthatch regime}

Hatching eggs from Arbor Acres parent stocks that were 37, 44, and 67 weeks of age, were stored for less than 5 days under commercial condition of $18^{\circ} \mathrm{C}$ and 70 relative humidity. Eggs were examined and any eggs with shell abnormalities were fiscarded. Three hundred eggs from each parent's age group weighing between 60 to $65 \mathrm{~g}$ were set in a forced air incubator, following standard hatchery protocol.

On the $18 t h$ day of incubation, the eggs were examined by canding, and eggs with viable embroys were transferred to hatching baskets. All chicks were removed from the hatcher at 21 days plus 6 hrs of incubation for sufficient dryness and thereafter were Wingbanded. Haif of the chicks from each parent stock were removed to the rearing pen (removed group) while the remaining chicks were kept in the hatcher for additional 30 hours posthatch (held group). The experiment was conducted in four replicates, each containing 50 broiler chicks from each parent age group (half removed and half held). The chicks were placed in floor pens. Feed (21\% protein, 3000 k.cal $\mathrm{ME} / \mathrm{Kg}$ ) and water were provided ad lebitum and received continous illumination throughout the experiment.

\section{Physiological parameters}

Twenty chickls (10 removed and 10 held) from each parent age group were weighed and sacrificed prior to placement, residual yolk was removed and expressed as relakive weight [grams of yoik/100 grams of live body weight (BW)]. At 2, 4, and 6 weeks of age ten chicks from each age ( 5 removed and 5 held) were sacrificed, bursa of fabricious and spleen were removed and expressed as relative weight (milligram of organ/tco grams of EW). Prior to sacrifice, blood samples were collected by cardiac puncture and packed cell volume (PCV) wers measured using heparinized microhematocrite tubes.

\section{Inmusaization}

All chicks were vaccinated at 5 days of age against Newcastle disease (ND) using eye drop method with $B 1$ strain vaccine and revaccinated at 10 days of age by $0.5 \mathrm{ml}$ Newcastle inactivated oil base vaccine injected under the skin on the back of the neck. Blood samples were collected by cardiac puncture at placing time to detect maternal immunity) and at 2, 3, 4, 5 and 6 weeks of age. Antibody titter was monitored by hemagglutination inhibition (H1) test (Beard 1980). At 6 weeks of age 30 chicks from aach parent's age group ( 15 from each posthatch treatment) were injected with $0.2 \mathrm{ml}$, $9 \%$ suspension of sheep red blood cells. Blood samples were collected 7 days post injection and antibcdy titter against (SRBC) were determined 
using the microtitter procedure discribed by Van Der Zijpp and Leenstra (1980).

\section{Statistical analysis of data:}

The data were analyzed using the SAS (1988) General Linear Models Procedure with a two-way ANOVA model using age of parent and hatching hoiding time as main effects. Where appropriate, means were separated using Duncan's multiple range test.

\section{RESULTS AND DISCUSSION}

\section{Residual yolk}

Regardless of parnt's age, the relative weight of residual yolk was significantly lower in held chicks when compared with newly hatched removed chicks (Figure 1.). The results elucidated that after $30 \mathrm{hrs}$ holding the reduction in relative weight of residual yolk was affected by the age of parent so the residual yolk was reduced to $53.1,65.8$, and $44.0 \%$ for chicks hatched from 37,44 , and 67 -week-old hens eggs. This observation is consistent with the result of Pinchasov and Noy (1993). Who reported that holding chicks for 48 hrs reduced the residual yolk to approximately half of its initial posthatch weight. The relative weight of residual yolk was positively increased with the age of parent, the chicks hatched from 67 -week-old hens had significantly higher relative residual yolk weight than those hatched from 37-week-old (in both held and removed chicks) and 44-weeks-old hens eggs (in held chicks only), even though they were hatched from older breeder would tend to give a greater mass of egg components, leading to a relatively greater yolk size (Washburn and Guill, 1974; Shanawany, 1984; Yannakopoulos and Tserveni-Gousi, 1987; O'Sullivan et al., 1991).

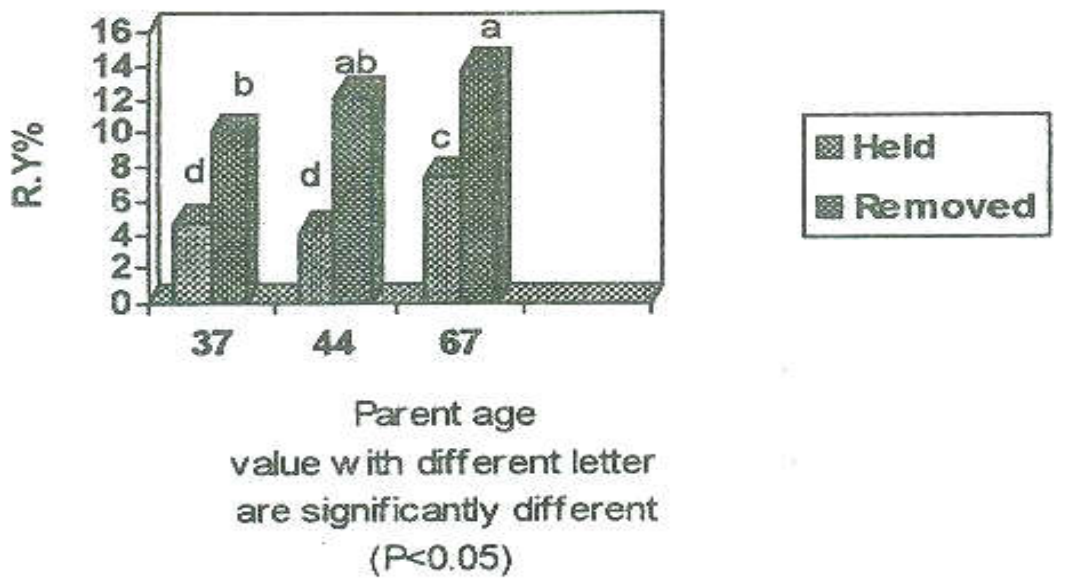

Figure 1 Mean residual yolk (RY) percentage as influenced by posthatch holding time and parent age. 
Relative bursa and spleen weight.

Relative bursa weight (RBW) was smaller (not significant) for held chicks when compared with removed chicks in all cases of the experiment (Table 1), except those hatched from the youngest hens which gave opposite results at 2 and 6 weeks of chicks age. At 6 weeks of age the held chicks hatched from 44 weeks hens had smaller RBW than those conterpart of removed chicks.

Held chicks also had smaller relative spleen weight (RSW) at 2, 4, or 6 weeks than those counterparts of removed chicks that hatched from 37,44 , or 67 -week-old hens, respectively, (Table 2). Glick (1967) stated that the fallure of normal spleen development was correlated with the inhibition of bursal development. The present results correspond with those of Wyatt et al. (1986) who reported that both RBW and RSW were significantly reduced through 14 days of age when chicks were held in the incubator for an additional 30 hrs.

Table 1. Influence of posthatch holding time and parent age on relative bursa we

\begin{tabular}{lcccc}
\hline Chick age & Posthatch & \multicolumn{3}{c}{ Parent age (week) } \\
\cline { 3 - 5 } (weeks) & reatment & 37 & 44 & 67 \\
\hline 2 & held & $315 \pm 31 \mathrm{a}$ & $253 \pm 41 \mathrm{a}$ & $264 \pm 22 \mathrm{a}$ \\
\hline \multirow{2}{*}{4} & removed & $250 \pm 45 \mathrm{a}$ & $270 \pm 15 \mathrm{a}$ & $259 \pm 43 \mathrm{a}$ \\
& held & $182 \pm 41 \mathrm{a}$ & $220 \pm 50 \mathrm{a}$ & $212 \pm 60 \mathrm{a}$ \\
\hline 6 & removed & $42 \pm 5 \mathrm{bc}$ & $119 \pm 13 \mathrm{a}$ & $62 \pm 7 \mathrm{bc}$ \\
& held & $75 \pm 4 \mathrm{bc}$ & $82 \pm 12 \mathrm{~b}$ & $46 \pm 9 \mathrm{c}$ \\
\hline
\end{tabular}

Value within each age of chicks with different letters are significantly different $(P<0.05)$.

Table 2. Influence of posthatch holding time and parent age on relative spleen weight

\begin{tabular}{lcccc}
\hline Chick age & Posthatch & \multicolumn{3}{c}{ Parent age (week) } \\
\cline { 3 - 5 } (weeks) & treatment & 37 & 44 & 67 \\
\hline 2 & removed & $87 \pm 10$ & $76 \pm 10$ & $76 \pm 8$ \\
& held & $77 \pm 11$ & $62 \pm 18$ & $66 \pm 15$ \\
\hline 4 & removed & $157 \pm 35$ & $154 \pm 16$ & $199 \pm 33$ \\
& held & $170 \pm 19$ & $134 \pm 11$ & $198 \pm 38$ \\
\hline 6 & removed & $176 \pm 28$ & $131 \pm 19$ & $191 \pm 52$ \\
& held & $182 \pm 12$ & $205 \pm 31$ & $128 \pm 20$ \\
\hline
\end{tabular}


Changes in gland weight are possibly due to the release of corticosterone during the extended period in which hatched chicks are exposed to incubation temperature (Wyatt et al., 1986). This interpretation could be confirmed by the Finding of Edens and Siegel (1975) who reported that significant changes occurred in plasma corticosterone levels of chicks exposed to high environmental temperature. Also, this interpretation is consistent with results reported by Siegel (1961; 1962) who showed that $\mathrm{ACTH}$ injection, resulted in depressed bursa and spleen weight. The results from the present study indicate that these target organs are responsive to environmental stress at an early age.

At 2 weeks of age, the RBW of removed chicks increased with the age of parent, thereafter the RBW of chicks hatched from 44 weeks-old-hens ranked first with significant differences at 6 weeks of age than that from other parent groups. On the other hand, there was no influence of parent age on RSW at any time.

\section{Hematocrit (PCV)}

Held chicks hatched from 37-old-hens had greater PCV, at one day of age, compared with removed chicks (Table 3), however the difference was not statistically significance. This finding may be attributed to increased hemoconcentration and excessive dehydration caused by extended holding in the hatcher. Similar results were observed by Wyatt et al. (1986). On the othe hand, inverse result was observed at one day of age between held and removed chicks of the other hens groups. It seems that held chick hatched from 44 and 67 weeks-old-hens suffered from degradation of the residual yolk only, wherease the held chicks hatched from 37 weeks-old-hen suffered from both dehydration plus degradation of residual yolk. Generally, no differences were observed in PCV after one day of age between held or removed chicks; except at 6 weeks of age the held chicks hatched from 67 weeksold-hen had significantly lower PCV than those counterparts of unheld ones. On the other hand, there were no effect of parent age in PCV at any time.

Table 3. Influence of posthatch holding time and parent age on heamatocrit value

\begin{tabular}{|c|c|c|c|c|}
\hline \multirow{2}{*}{$\begin{array}{l}\text { Chick age } \\
\text { (weeks) }\end{array}$} & \multirow{2}{*}{$\begin{array}{l}\text { Posthatch } \\
\text { treatment }\end{array}$} & \multicolumn{3}{|c|}{ Parent age (week) } \\
\hline & & 37 & 44 & 67 \\
\hline & removed & $26.7 \pm 1.0 \mathrm{a}$ & $29.3 \pm 0.9 a$ & $27.3 \pm 1.3 a$ \\
\hline \multirow{3}{*}{$0^{*}$} & & & & \\
\hline & held & $30.0 \pm 1.0 a$ & $28.7 \pm 0.6 a$ & $26.8 \pm 1.3 a$ \\
\hline & removed & $28.6 \pm 1.0 a$ & $27.4 \pm 1.0 a$ & $27.5 \pm 1.0 a$ \\
\hline \multirow{2}{*}{2} & held & $26.8 \pm 1.0 a$ & $28.6 \pm 1.0 a$ & $29.8 \pm 0.1 a$ \\
\hline & removed & $31.2 \pm 0.5 a$ & $28.8 \pm 1.0 a$ & $29.4 \pm 0.4 a$ \\
\hline \multirow{2}{*}{4} & held & $29.2 \pm 1.0 a$ & $30.4 \pm 0.6 a$ & $28.8 \pm 2.0 a$ \\
\hline & removed & $29.8 \pm 1.0 a b$ & $28.6 \pm 1.0 a b$ & $34.0 \pm 1.0 a$ \\
\hline 6 & held & $30.0 \pm 1.0 \mathrm{ab}$ & $30.8 \pm 0.4 a b$ & $26.3 \pm 2 . b$ \\
\hline
\end{tabular}




\section{Antibody titter}

Generally; removed chicks responded better to SRBC and produced higher. although not significant, antibody than those of held chicks (Figure 2). The lower immune response of held chicks is mostly due to the stress of excess heating and water deprivation of birds exposed early in hatcher for 30 hours, which in turn interrput the development of bursa (primary lymphoid organs) and spleen (secondary lymphoid organs). Wyatt et al. (1986) and Casteel et al. (1994) reported immunesuppression associated with posthatch holding in the hatcher and attributed this phenomenon to the elevation in ACTH. Regardless of treatment, the antibody titter against SRBC was positively related with the age of parent.

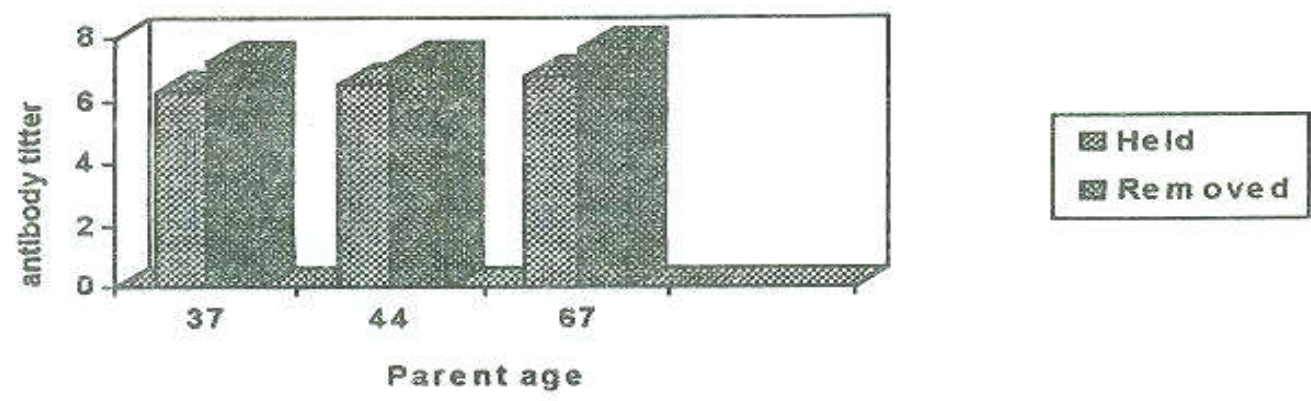

Figure 2. Mean antibody titter against SRBC as infuenced by posthatch treatment and parent age.

Generally, held chicks had significantly elevated maternal antibody titter (at day of placement) against Newcastle disease vaccine (NDV) when compared with removed chicks (Figure 3), this phenomenon may be attributed to that holding treatment increased the transimition of maternal antibodies from yolk sac [the pathway of maternal immunity (Gordon and Jordan, 1982)] to blood stream. On the other hand, neither age of parent nor holding chicks in hatcher affected the antibody titter against NDV at the successive ages of the chicks (Figure 4).

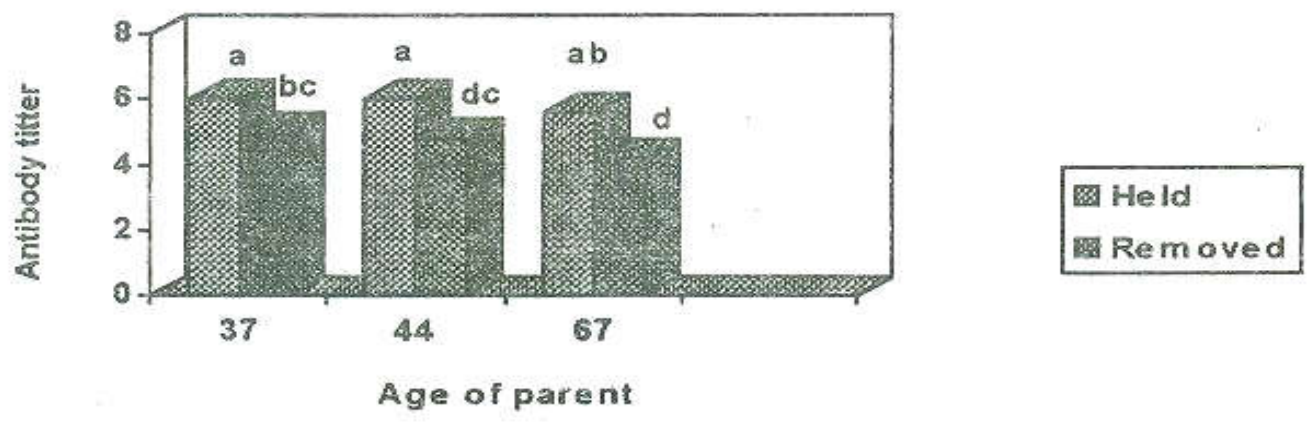

Figure 3. Maternal antibody titter against NDV as influenced by posthatch treatment and parent age. 


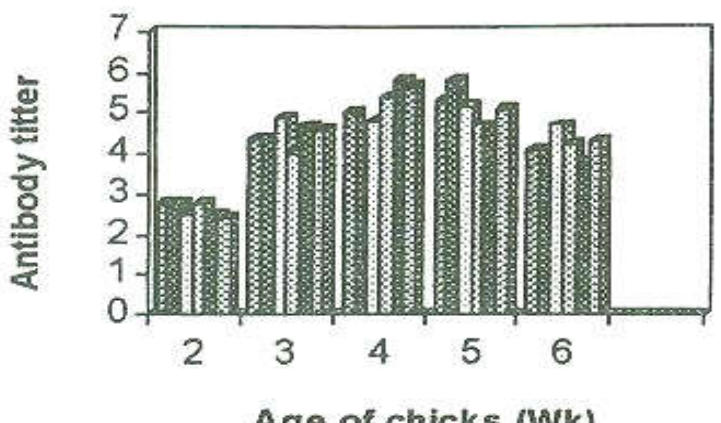

\begin{tabular}{|c|}
\hline 学 Held(37) \\
\hline $\mathrm{Re}$ \\
\hline 图 H \\
\hline 阅 \\
\hline 图 Held(67) \\
\hline noved \\
\hline
\end{tabular}

Age of chicks (Wk)

Figure 4. Mean antibody titter against NDV as influenced by posthatch treatment and parent age

\section{REFERENCES}

Bread, C.W., 1980. Serologic procedures. Page 129-135. In: Isolation and identification of Avian pathgens. Edit by B. Hitchner, , C.H. Domernuth, H.G. purchase and J.E. Williams, ed. AM. Assoc. Avian pathol. Inc. Endwell, NY, USA.

Casteel, E.T., J.L. Wilson, R.J. Buhr, and J.E. Sander, 1994. The influence of extended posthatch holding time and placement density on broiler performance. Poultry Sci., 73:1679-1684.

Edens, F.W. and H.S. Siegel, 1975. Adrenal responses in high and low ACTH response lines of chickens during acute heat stress. J. Immunol. 98:1076-1084.

Glick, B., 1967. Antibody and gland studies in cortison and ACTH-injected birds. J. Immunol. 98:1076-1084.

Gordon, R.E. and F.T.W. Jordan, 1982. Poultry diseases. Second edition. 335-336.

Hager, J.E. and W.L. Bean, 1983. Posthatch incubation time and early growth of broiler chickens. Poultry Sci., 62:247-254.

Hays, F.A. and E.W. Spear, 1952. Relation of age of parents to mortality and sex ratio of chicks at eight weeks. Poultry Sci., 31:792-795.

Kingston, D.J.1979. Some hatchery factors involved in early chick mortality. Aust. Vet. J. 55:418-421.

McNaughton, J.L., J.W. Deaton, F.N. Reece and R.L. Haynes, 1978. Effect of age of parents and hatching egg weight on broiler chicks mortality. Poultry Sci., 57:3844.

Moran, E.T. JR. and B.S. Reinhart, 1980. Yield, quality and subsequent performance of poults removed from the hatchery using early-late and complete collection procedures. Poultry Sci., 59:1918-1924.

O'Sullivan, N.P., E.A. Dunnington and BP. Siegel, 1991. Relationships among age of dam, egg components embryo lipid transfer and hatch ability of broiler breeder eggs. Poultry Sci., 70:2180-2185. 
Pinchasov, Y. and Y. Noy, 1993. Comparison of posthatch holding time and subsequent early performance of broiler chicks and turkey poults. Br. Poult. Sci., $34: 111-120$.

SAS Institute, 1988. SAS/Stat User's Guide: Statistics SAS Institute, Inc., Cary, NC, USA.

Shanawany, M.M, 1984. Inter-relationship berween egg weight, parental age and ambryonic development. Br. Poult. Sci, 25:449-455.

Siegel, H.S., 1961. Age and sex modification of responses to adrenocorticotropin in young chickens. 1. Changes in adrenal and lymphatic gland weights. Poultry Sci., 40:1253-1274.

Siegel, H.S., 1962. Age and sex modification of responses to adrenocorticotropin in young chickens. 1. Changes in adrenal cholesterol and blood constituent levels. Poulliry Sci, 41:311-334.

Sinclair, R.W., F.E. Robinson and R.T. Hardin, 1990. The effects of parent age and positatch treatment on broiler performance. Poultry Sci., 69:526-534.

Van der Zijpp, A.J. and F.R. Leenstra, 1980. Genetic analysis of the humoral immune response of white leghorn chicks. Poultry Sci. 59:1383-1369.

Washbum, KW. and R.A. Guill, 1974. Relationship of embryo weight as a percent of egg weight to efticiency of feed utilization in the hatched chick. Poultry Sci., 53:766-769.

Waytt, C.L. W.D. Weaver, Jr. and W.L. Beane, 1985. Influence of egg size, egg shell quality and posthaxich holding time on broiler performance. Poultry Sci., 64:20492055.

Wayt, C.L., W.D. Weaver, Jr., W.L. Beane and D.M. Denbow, 1986. Influence of hatch holding time on several physiological parameters associated with the immune system of chickens. Poultry Sci., 65:2156-2164.

Yannakopoulos, A.L. and A.S. Tserveni-Gousi, 1987. Relationships of parent's age, hatching egg weight and shell quality to dayold chick weight as influenced by oviposition time. Poultry Sci., 68:829-833. 


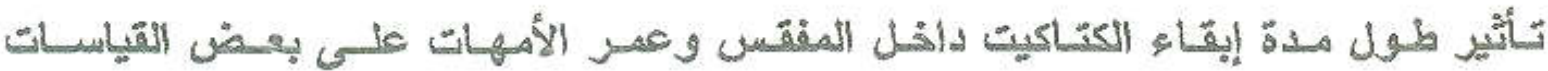

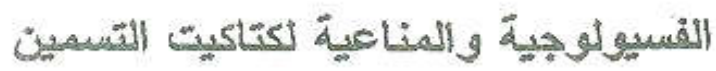

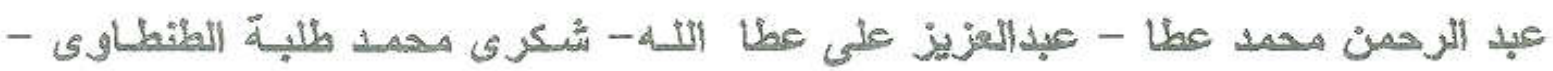

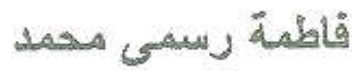

قسم الإنتاج الحيو النى، كلية الزر اعة ، جاهمة القاهرة، المجيزة

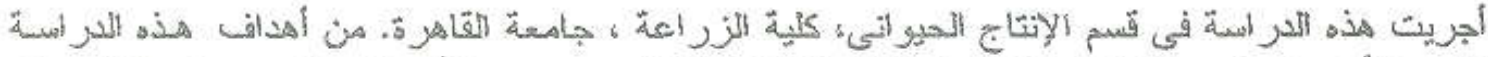

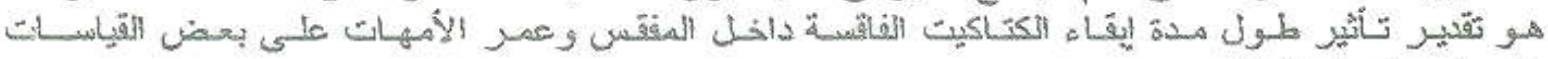

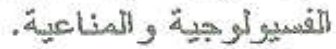

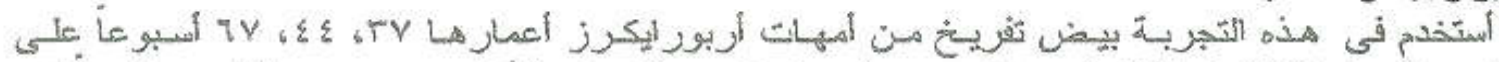

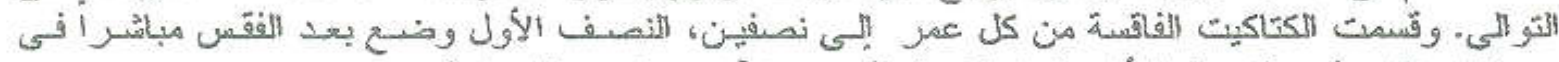

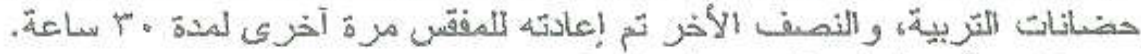

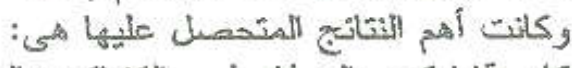

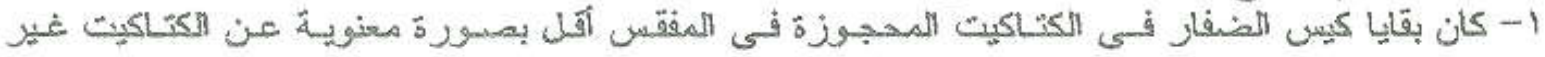

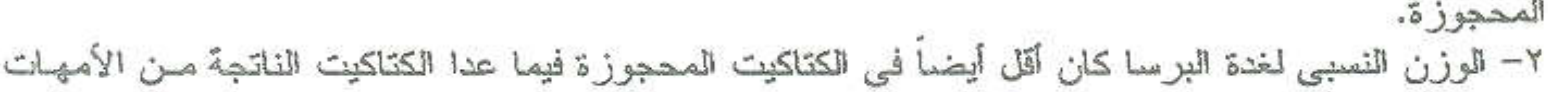

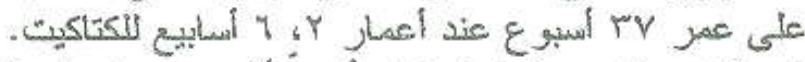

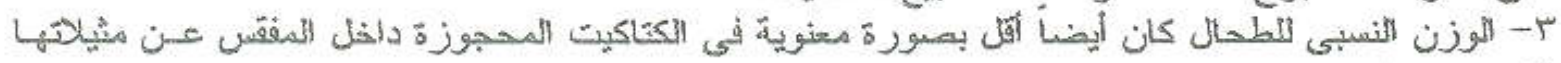

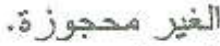

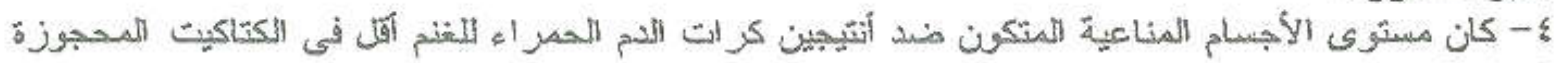

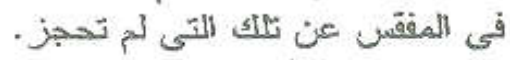

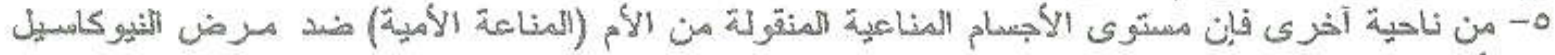

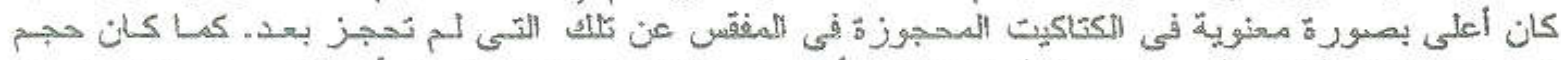

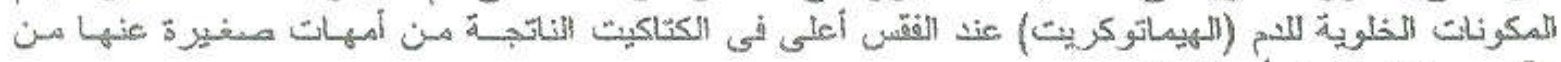

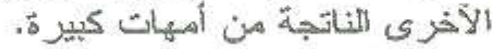

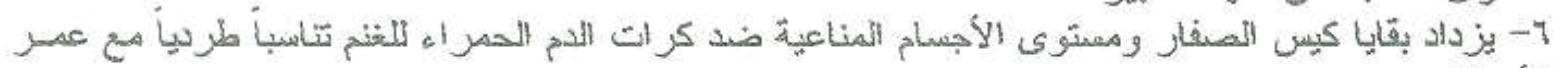

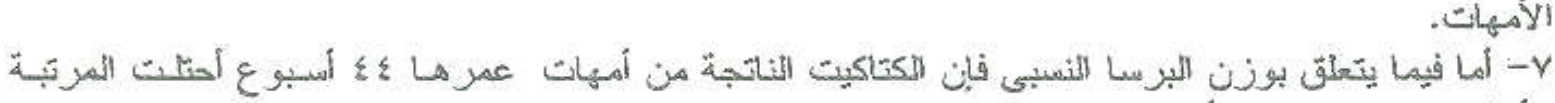

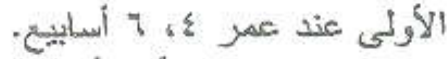

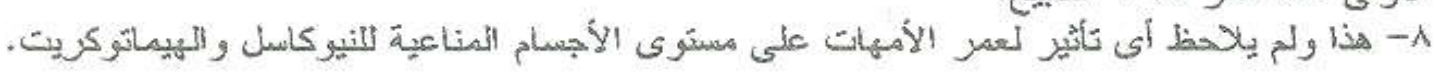

